\title{
BMJ Open Evidence for a persistent, major excess in all cause admissions to hospital in children with type-1 diabetes: results from a large Welsh national matched community cohort study
}

\author{
Adrian Sayers, ${ }^{1}$ Daniel Thayer, ${ }^{2}$ John N Harvey, ${ }^{3}$ Stephen Luzio, ${ }^{4}$ \\ Mark D Atkinson, ${ }^{2}$ Robert French, ${ }^{5}$ Justin T Warner, ${ }^{6}$ Colin M Dayan, ${ }^{7}$ \\ Susan F Wong, ${ }^{7}$ John W Gregory ${ }^{7}$
}

To cite: Sayers A, Thayer D, Harvey JN, et al. Evidence for a persistent, major excess in all cause admissions to hospital in children with type1 diabetes: results from a large Welsh national matched community cohort study. BMJ Open 2015;5:e005644. doi:10.1136/bmjopen-2014005644

- Prepublication history and additional material is available. To view please visit the journal (http://dx.doi.org/ 10.1136/bmjopen-2014005644).

AS and DT contributed equally.

Received 7 May 2014 Revised 24 October 2014 Accepted 30 October 2014

CrossMark

For numbered affiliations see end of article.

Correspondence to Adrian Sayers;

Adrian.sayers@bristol.ac.uk

\section{ABSTRACT}

Objectives: To estimate the excess in admissions associated with type1 diabetes in childhood.

Design: Matched-cohort study using anonymously linked hospital admission data.

Setting: Brecon Group Register of new cases of childhood diabetes in Wales linked to hospital admissions data within the Secure Anonymised Information Linkage Databank.

Population: 1577 Welsh children (aged between 0 and 15 years) from the Brecon Group Register with newly-diagnosed type-1 diabetes between 1999-2009 and 7800 population controls matched on age, sex, county, and deprivation, randomly selected from the local population.

Main outcome measures: Difference in all-cause hospital admission rates, 30-days post-diagnosis until 31 May 2012, between participants and controls.

Results: Children with type- 1 diabetes were followed up for a total of 12102 person years and were at $480 \%$ (incidence rate ratios, IRR $5.789,(95 \% \mathrm{Cl} 5.34$ to 6.723), $p<0.0001$ ) increased risk of hospital admission in comparison to matched controls. The highest absolute excess of admission was in the age group of $0-5$ years, with a $15.4 \%$ (IRR 0.846 , (95\% $\mathrm{Cl} 0.744$ to 0.965$), p=0.0061$ ) reduction in hospital admissions for every 5 -year increase in age at diagnosis. A trend of increasing admission rates in lower socioeconomic status groups was also observed, but there was no evidence of a differential rate of admissions between men and women when adjusted for background risk. Those receiving outpatient care at large centres had a 16.1\% (IRR $0.839,(95 \% \mathrm{Cl} 0.709$ to 0.990$), p=0.0189)$ reduction in hospital admissions compared with those treated at small centres.

Conclusions: There is a large excess of hospital admissions in paediatric patients with type-1 diabetes. Rates are highest in the youngest children with low socioeconomic status. Factors influencing higher admission rates in smaller centres (eg, "out of hours

\section{Strengths and limitations of this study}

- Strengths of this study include the large, nationally representative and nearly complete coverage of paediatric patients with type-1 diabetes with a matched control group.

- Further strengths include the integration of multiple registries, allowing all-cause hospital admission rates in young people with diabetes to be investigated, and the use of multilevel Poisson models to appropriately account for clustering within matching sets and the population.

- Limitations also include the potential existence of other covariables that predict hospital admission rates which were not included in the analysis. We do not have the ability to include individual specific indicators of glycaemic control such as glycated haemoglobin, or unit specific level covariates which may explain differences in admission rates between large and small centres.

resources") need to be explored with the aim of targeting modifiable influences on admission rates.

\section{INTRODUCTION}

The incidence of type- 1 diabetes (T1D) in childhood is increasing $3-4 \%$ per annum, more so in pre-school-aged, ${ }^{1}$ leading to increasing demands on services. The management of T1D in childhood is demanding due to a complex treatment regimen. It is unsurprising that complications of suboptimal management, such as hypoglycaemia and ketoacidosis occur, leading to hospitalisation.

In the UK, there is increasing emphasis on delivering childhood diabetes services in 
outpatient settings with potential loss of expertise among ward staff. This may be a risk factor for deficient inpatient care of hypoglycaemia or diabetes in the perioperative period which has been identified. ${ }^{2}$ Understanding how often children with T1D are admitted to hospital will inform the training requirements for ward staff. Caring for all ages with diabetes is expensive, costs of acute hospital care having risen dramatically over the last decade and now account for over $12 \%$ of all healthcare revenue in Wales. ${ }^{3}$ There are few published data on costs of healthcare services for children with T1D, though hospitalisation has a large impact on these. ${ }^{4}$ None of the 14 standards in the Best Practice Tariff for Paediatric Diabetes used in England to define commissioning of children's diabetes services, refer specifically to the needs of those hospitalised. ${ }^{5}$ National audits of childhood diabetes focus mostly on glycated haemoglobin (HbA1c) data, diabetes-related complications such as ketoacidosis and aspects of the outpatientbased service process rather than wider inpatient care issues including all-cause readmission rates. ${ }^{6}$ Furthermore, although adherence to guidelines for diabetes care can improve HbAlc and outpatient care process measures, there is no evidence of beneficial impacts on hospitalisation. ${ }^{7}$

In Wales since 1995, the Brecon Group, a network of healthcare professionals caring for children and young people with diabetes normally resident in Wales, has systematically collected data on diagnosis. ${ }^{8}$ Knowledge of inpatient service usage (frequency and risk factors) is important to guide the development of clinical services and minimise the burden of unnecessary admissions on families and healthcare resources. These data may also provide a measure of ongoing improvements in the quality of paediatric diabetes care which may lead to reduced rates of ketoacidosis and its associated mortality. ${ }^{9}$

The aims of this study are to compare hospital admission rates of children and young adults with T1D diagnosed in childhood to a matched cohort of individuals without diabetes and explore factors influencing hospital admissions rates.

\section{METHODS}

\section{Study design, setting and source of data}

Using a record-linkage study design, we conducted a matched-cohort study of admission rates (from the Patient Episode Database for Wales (PEDW)) in those newly diagnosed with T1D in childhood identified from the Brecon Group register ${ }^{8}$ and controls without diabetes in the Secure Anonymised Information Linkage (SAIL) Databank held in the Health Information Research Unit at Swansea University. ${ }^{10}$ The Brecon Group register is intended to include all children developing T1D before their 15th birthday while living in Wales and the completeness of ascertainment evaluated in 2006 and 2013 by contacting all 530 General Practices in Wales for a list of children with diabetes under their care who would meet the inclusion criteria for the register. A two-source capture-recapture model was used to estimate the size of the total diabetic population for each period ${ }^{11}$ and showed ascertainment to be $97.6 \%$ and $98 \%$, respectively. Each participant was matched with five randomly selected controls based on gender, county of residence, quintile of socioeconomic status (SES) ${ }^{12}$ and week of birth ( \pm 2 weeks) as recorded in the NHS Wales Administrative Register. ${ }^{13}$

\section{Participants}

Participants with T1D diagnosed aged under 15 years from 1999 to 2009 were matched to unaffected population controls selected from NHS administrative data (further information on data sources in online supplementary material).

\section{Primary outcome and exposure}

The primary outcome of interest is difference in hospital admission rates, post 30 days from diagnosis, between participants and controls (further definitions of admission in online supplementary material).

\section{Potential confounders}

Covariates of interest included age and year of birth, gender, county of residence, quintiles of area level SES (coded from 1(highest) to 5(lowest)), treatment centre size and urban or rural habitation (using an Office for National Statistics definition of an urban locale as a census Output Area with a population of over 10000$).{ }^{14}$ Treatment centres where patients were initially diagnosed were defined as either large (referring to three hospitals in South Wales, each of which treated more than $10 \%$ of Welsh children with T1D) or small. Provenance of each covariate of interest is by case and control status and is listed in the online supplementary table S1.

\section{Statistical methods}

Population level characteristics of the Brecon Group Register were described using cross tabulation of frequencies of individuals in specific strata, and simple person time incident rates (PTIR) in cases and controls, and at different levels of the exposures of interest were calculated.

\section{Modelling strategy}

A multilevel over dispersed Poisson model was used to estimate the difference in rate of admissions between children and young adults with diabetes compared to the non-diabetic population. Results are reported as incidence rate ratios (IRR), with $95 \%$ posterior probability intervals and directional posterior probabilities.

Unadjusted models were used to investigate the crude difference in the rate of admissions between cases and controls. The matched-cohort design of the study was incorporated into the analysis using a multilevel modelling approach. 
The effect of covariates was investigated by introduction of an interaction between the covariate of interest and case-control indicator variable. Results from the model interactions are reported. The effect of a covariate on the difference in the rate of admissions between cases and controls was assessed using the Deviance Information Criterion (DIC), comparing the simple and covariate-adjusted model and the directional posterioal probability that the parameter is the wrong side of the null. The effect of county was investigated by the introduction of an additional higher-level random effect into the model and models were similarly compared using the DIC.

Significant covariates were carried forward into more completely adjusted models, and model simplifications including treating SES and age at diagnosis as an ordered categorical variable were also considered.

The use of multilevel modelling is necessary as it controls for a number of design elements within the study. Typically multilevel models are often taught with reference to administrative structures (ie, patients nested within hospitals which are in turn nested in administrative regions). The primary reason to conduct a multilevel analysis is to allow for this structure and ensure unbiased estimates are achieved. In this study multilevel models were used for similar reasons. However, the first reason to use a multilevel model is to relax the assumptions of a Poisson model. In a Poisson model the mean is constrained to be equal to the variance and therefore like many other generalised linear models the level 1 residual variance is not estimated. However, using multilevel models allows for a hyper-variance parameter to be estimated, thereby directly testing the assumptions of a Poission model and allowing for overdispersion. ${ }^{15}$ The second reason to use a multilevel model is to correct the sample size due to matched cohort design. The sample size can be artificially inflated by selecting more control participants for each case which will tend to lead to spurious precision. The use of multilevel models corrects this by modelling the correlation between the control sets. The third reason to use multilevel models is to allow for any regional correlation in patterns of treating patients which may lead to higher or lower rates of hospital admissions. Further details of the multilevel modelling approach are provided in online supplementary material and introductory texts which explain the context of multilevel modelling are available. $^{15}$

\section{Sensitivity analysis}

To explore the effect of possible missing admission data when comparing rate of admissions to hospital, we investigated the effect of continuous residency throughout the period of interest and residence in a border county. Analyses were repeated and additionally restricted to individuals continuously resident throughout the period of interest and those not living in a border county. Continuous residency was defined as having no gaps during the study period of greater than 30 days between Welsh addresses and individuals living in a Welsh county bordering England were excluded from the analysis.

All analyses were performed using MLwiN ${ }^{16}{ }^{17}$ via the runmlwin command ${ }^{18}$ in Stata V.12.1. ${ }^{19}$ The majority of analyses were estimated using Markov Chain Monte Carlo (MCMC) methods due to their superior performance in multilevel generalised linear models. ${ }^{20}$ Additionaly, effective sample size (ESS) is also reported to indicate the amount of chain mixing. When posterior chain mixing is low (less than 500) there is some doubt in the reliability of the estimates. Results are reported as IRR comparing cases to controls. For example, an IRR of 1.2 would represent a $20 \%$ difference in rate of admissions between cases and controls. Ninety five per cent posterior intervals are interpreted as the range we would expect the true parameter to lie within, $95 \%$ of the time. Directional posterior probabilities are reported as opposed to $p$ values to avoid the commonly misheld interpretation of a $p$ value that it provides evidence that the parameter is the wrong side of the null hypothesis of no effect. ${ }^{21}$

\section{RESULTS}

\section{Descriptive analyses}

There were 855 boys and 722 girls identified with T1D from the Brecon register with matched data in the SAIL Databank. Individuals were well distributed across all regions of Wales, with similar numbers of individuals within each stratum of social economic position. Just over one-fifth of individuals had an age of onset of T1D less than 5 years, whereas two-fifths had an age of onset greater than 10 years (table 1 ).

Thirty eight per cent of individuals were treated from diagnosis at large centres, most living near the three largest cities in South Wales. Approximately equal numbers of individuals from urban $(52 \%)$ and rural $(48 \%)$ locations were treated at small centres. However, most of those treated at large centres lived in urban locales $(78 \%)$.

As controls were selected to have the same distribution of covariates as cases, details are not presented.

Individuals from the Brecon cohort had a total of 12 102.4 years of follow-up with a total 6359 admissions to hospital, representing half an admission per person per year. On average children had 7.67 (median 7.53; IQR $5.05,10.37$ ) and 7.55 (median 7.46; IQR 4.88, 10.36) years of follow-up time in patients with and without T1D, respectively.

\section{Crude analysis of admission rates}

Simple PTIR per year of follow-up are presented in table 2. These results illustrate that there is a large excess in admissions in patients with T1D compared to population controls. Similarly, the admission rate in boys with T1D is higher in comparison to girls with T1D. A similar pattern is also seen in population controls. There is a strong trend in 
Table 1 Demographic characteristics of individuals with type I diabetes selected from the Brecon cohort

\begin{tabular}{|c|c|c|c|c|c|}
\hline \multirow[b]{2}{*}{ Variable } & \multirow[b]{2}{*}{ Follow-up time (years) } & \multicolumn{2}{|c|}{$\begin{array}{l}\text { All cases } \\
\mathrm{N}=1577 \\
12102.4\end{array}$} & \multicolumn{2}{|c|}{$\begin{array}{l}\text { Cases (Continuous } \\
\text { residency) Excluded } \\
\text { border county } \\
N=1340 \\
10270.9\end{array}$} \\
\hline & & $\mathbf{N}$ & Per cent & $\mathbf{N}$ & Per cent \\
\hline Matching ratio & $1: 1$ & 3 & $(0.19)$ & 2 & $(0.15)$ \\
\hline \multirow{4}{*}{ Cases: controls } & $1: 2$ & 11 & $(0.70)$ & 10 & $(0.74)$ \\
\hline & $1: 3$ & 15 & $(0.95)$ & 16 & (1.19) \\
\hline & $1: 4$ & 10 & $(0.63)$ & 14 & $(1.04)$ \\
\hline & $1: 5$ & 1538 & (97.53) & 1298 & (96.87) \\
\hline \multirow[t]{2}{*}{ Sex } & Male & 855 & (54.22) & 727 & (54.25) \\
\hline & Female & 722 & (45.78) & 613 & (45.75) \\
\hline \multirow[t]{5}{*}{ Socioeconomic status } & 1 & 302 & (19.15) & 237 & (17.69) \\
\hline & 2 & 307 & (19.47) & 222 & (16.57) \\
\hline & 3 & 310 & (19.66) & 282 & (21.04) \\
\hline & 4 & 328 & (20.80) & 287 & (21.42) \\
\hline & 5 & 330 & (20.93) & 312 & (23.28) \\
\hline \multirow{2}{*}{ Centre size } & Small centre & 970 & (61.51) & 767 & (57.24) \\
\hline & Large centre & 607 & (38.49) & 573 & (42.76) \\
\hline \multirow[t]{3}{*}{ Age@diagnosis (years) } & $<5$ & 374 & (23.72) & 320 & (23.88) \\
\hline & $5-10$ & 600 & (38.05) & 505 & (37.69) \\
\hline & $>10$ & 603 & (38.24) & 515 & (38.43) \\
\hline \multirow[t]{2}{*}{ Urbanisation } & Rural & 538 & (34.12) & 417 & (31.12) \\
\hline & Urban & 1039 & (65.88) & 923 & (68.88) \\
\hline \multirow[t]{22}{*}{ County } & Blaenau Gwent & 49 & (3.11) & 49 & (3.66) \\
\hline & Bridgend & 86 & (5.45) & 86 & (6.42) \\
\hline & Caerphilly & 118 & (7.48) & 118 & (8.81) \\
\hline & Cardiff & 133 & (8.43) & 133 & (9.93) \\
\hline & Carmarthenshire & 84 & (5.33) & 84 & (6.27) \\
\hline & Ceredigion* & 41 & (2.60) & 41 & (3.06) \\
\hline & Conwy* & 56 & (3.55) & 56 & (4.18) \\
\hline & Denbighshire* & 58 & (3.68) & 57 & (4.25) \\
\hline & Flintshire $\dagger$ & 86 & (5.45) & & \\
\hline & Gwynedd* & 65 & $(4.12)$ & 65 & $(4.85)$ \\
\hline & Isle of Anglesey & 40 & (2.54) & 40 & (2.99) \\
\hline & Merthyr Tydfil & 30 & (1.90) & 30 & (2.24) \\
\hline & Monmouthshire $\dagger$ & 50 & (3.17) & & $(0.00)$ \\
\hline & Neath Port Talbot & 78 & (4.95) & 77 & $(5.75)$ \\
\hline & Newport & 78 & (4.95) & 78 & (5.82) \\
\hline & Pembrokeshire* & 58 & (3.68) & 58 & $(4.33)$ \\
\hline & Powyst & 48 & (3.04) & & \\
\hline & Rhondda, Cynon, Taff & 118 & $(7.48)$ & 118 & $(8.81)$ \\
\hline & Swansea & 121 & (7.67) & 121 & $(9.03)$ \\
\hline & The Vale of Glamorgan & 76 & $(4.82)$ & 75 & $(5.60)$ \\
\hline & Torfaen & 54 & (3.42) & 54 & $(4.03)$ \\
\hline & Wrexham$†$ & 50 & $(3.17)$ & & \\
\hline \multirow[t]{5}{*}{ Date of birth } & $<90$ & 257 & (16.30) & 214 & (15.97) \\
\hline & $90-94$ & 496 & (31.45) & 417 & (31.12) \\
\hline & 95-99 & 535 & (33.93) & 466 & (34.78) \\
\hline & 00-04 & 236 & (14.97) & 197 & (14.70) \\
\hline & $>05$ & 53 & (3.36) & 46 & (3.43) \\
\hline \multirow[t]{2}{*}{ Residency } & Not continuous & 247 & $(15.66)$ & & \\
\hline & Continuous & 1330 & (84.34) & & \\
\hline
\end{tabular}

${ }^{*}$ Exclusive small centre.

†Border county.

‡Exclusive large centre. 
Table 2 PTIR per year of follow-up of all cause admissions to hospital in patients with type I diabetes and population controls, stratified by the exposures of interest

\begin{tabular}{|c|c|c|}
\hline & Controls & T1D \\
\hline All & 0.111 & 0.525 \\
\hline \multicolumn{3}{|l|}{ Sex } \\
\hline Male & 0.095 & 0.449 \\
\hline Female & 0.129 & 0.617 \\
\hline \multicolumn{3}{|l|}{ SES } \\
\hline 1 & 0.101 & 0.337 \\
\hline 2 & 0.109 & 0.479 \\
\hline 3 & 0.090 & 0.473 \\
\hline 4 & 0.119 & 0.608 \\
\hline 5 & 0.130 & 0.710 \\
\hline \multicolumn{3}{|l|}{ Centre size } \\
\hline Large centre & 0.114 & 0.486 \\
\hline Small centre & 0.108 & 0.551 \\
\hline \multicolumn{3}{|c|}{ Age@diagnosis (years) } \\
\hline$<5$ & 0.103 & 0.605 \\
\hline $5-10$ & 0.104 & 0.483 \\
\hline$>10$ & 0.122 & 0.519 \\
\hline \multicolumn{3}{|l|}{ Urbanisation } \\
\hline Rural & 0.105 & 0.434 \\
\hline Urban & 0.113 & 0.572 \\
\hline \multicolumn{3}{|l|}{ Date of birth } \\
\hline$<90$ & 0.125 & 0.575 \\
\hline $90-94$ & 0.117 & 0.457 \\
\hline $95-99$ & 0.093 & 0.503 \\
\hline 00-04 & 0.102 & 0.662 \\
\hline$>05$ & 0.153 & 0.796 \\
\hline \multicolumn{3}{|l|}{ Residency } \\
\hline Not continuous & 0.127 & 0.541 \\
\hline Continuous & 0.107 & 0.522 \\
\hline
\end{tabular}

PTIR, person time incident rates; SES, socioeconomic status; TID, type-1 diabetes. increasing admission rates by area level SES in patients with T1D with a similar patern of increase also observed in population controls. We also observe an increase rate of admissions in small centres in patients with T1D, whereas the same increase is not observed in population controls. Conversely, we also observe an increase in rate of admissions in urban versus rural areas in patients with T1D, whereas similar increases are not as evident in population controls. We also observe a general increase in admission rates with date of birth in patients with T1D and controls.

\section{Association between rate of admission to hospitals comparing cases to controls}

Table 3 , model 1 is a naive Poisson regression model which suggests there is a $375 \%$ increase in young people with diabetes' rate of admissions to hospital compared to controls. Using a multilevel model which allows the matched design of the study to be introduced, the rate of admissions was unchanged, but significant variance within the matching set was observed. The introduction of the hyper-variance parameter clearly illustrates data were overdispersed, and the assumption of the simple Poisson model that the mean is equal to the variance was violated. The (promoted) level 3 matched set variance parameter was stabilised, and there was a $388 \%$ increase in the rate of admissions to hospital.

Utilising an MCMC estimator with diffuse priors, the model was re-estimated, demonstrating a $480 \%$ increase in rate of admission to hospital. The SE of the IRR (precision) of the estimate was decreased, the level 3 set variance increased, whereas overdispersion variance reduced from 8.5 to 1.3 , indicating model misspecification was not as serious as previously thought. Given the dramatic differences and known problems of quasi-

Table 3 Incidence rate ratio of hospital admissions between individuals with type I diabetes compared to normal population controls using different model specification and estimation

\begin{tabular}{|c|c|c|c|c|c|c|c|c|c|c|c|}
\hline & \multirow[b]{2}{*}{ Model } & \multirow[b]{2}{*}{ IRR } & \multirow[b]{2}{*}{ (SE) } & \multirow[b]{2}{*}{$(95 \% \mathrm{Cl})$} & \multirow[b]{2}{*}{$\mathbf{p} \leq$} & \multirow[b]{2}{*}{ ESS } & \multicolumn{5}{|c|}{ Variances } \\
\hline & & & & & & & Level & Varia & ce (SE) & $(95 \% \mathrm{Cl})$ & ESS \\
\hline Unmatched & 1 & 4.756 & (1.027) & (4.600 to 4.918 ) & 0.0001 & & & & & & \\
\hline Matched & 2 & 4.744 & (1.028) & (4.582 to 4.912 ) & 0.0001 & & 2 & 1.012 & $(0.041)$ & (0.931 to 1.092$)$ & \\
\hline Over & 3 & 4.878 & (1.141) & (4.145 to 5.740 ) & 0.0001 & & 2 & 8.535 & $(0.156)$ & (8.229 to 8.842 ) & \\
\hline dispersed & & & & & & & 3 & 0.025 & $(0.065)$ & $(-0.103$ to 0.152$)$ & \\
\hline $\begin{array}{l}\text { MCMC over } \\
\text { dispersed }\end{array}$ & 4 & 5.789 & (1.075) & (5.343 to 6.273 ) & 0.0001 & 6551 & 2 & 1.267 & $(0.046)$ & (1.180 to 1.360$)$ & 7081 \\
\hline $\mathrm{DIC}=22370$ & & & & & & & 3 & 0.109 & $(0.023)$ & (0.066 to 0.157$)$ & 1647 \\
\hline
\end{tabular}

Model 1 is a single level Poisson model comparing the rates of hospital admission between individuals with type I diabetes compared to normal population controls estimated using quasi-likelihood approach. Model 2 is multilevel Poisson model which accounts for the matched design using a 2 level variance component model, estimated using quasi-likelihood approach. Model 3 is a multilevel Poisson model which accounts for the matched design and overdispersion using a 3 level variance component model, estimated using quasi likelihood. Results from models 1 to 3 are reported using maximum quasi-likelihood IRR, asymptotic SE, 95\% Cls and two-sided p values. Model 4 is the same as model 3, except estimated using MCMC. Results are reported using the mean of the posterior distribution to indicate IRR, the SD of the posterior chain is used to indicate the parameter SE, 95\% posterior probability intervals $(95 \% \mathrm{CI})$ represent the 2.5 th and 97.5 th centiles of the posterior distribution, and directional posterior probabilities $(p \leq)$. ESS indicates the effectiveness of MCMC chain mixing. Bayesian DIC is used to indicate model fit.

DIC, Deviance Information Criterion; ESS, effective sample size; MCMC, Markov Chain Monte; Carlo IRR, incidence rate ratio. 
likelihood estimators, the MCMC approach was used throughout.

\section{Interaction between T1D and covariates of interest comparing cases to controls \\ Unadjusted models}

Table 4 shows admission rates at different levels of covariates of interest comparing cases to controls. There was no difference in rate of admissions between sexes but large differences in rate of admissions between strata of area level SES, with a general increase in admission rates with lower area level SES. There is substantial support for inclusion of area level SES in further models with a reduction of the DIC by 20 points. Comparing differences in rate of admissions between those in large and small centres showed an $18 \%$ reduction in admission rate in large centres $(p=0.009)$. Age at diagnosis is inversely related to rate of admissions, with children aged 5-10 years having a 25\% reduction and children over 10 years having a $40 \%$ reduction in admissions compared to children under 5 years of age. There was a small but not significant increase in the admission rate between those in urban compared to rural locations The addition of a higher-level variance component, which represents county of diagnosis, resulted in a 10 point reduction in the DIC statistic, indicating that it explains a large proportion of the variance in the rate of admissions. There was a significant difference in admission rates observed with date of diagnosis (reduction in DIC of 35), yet the pattern was quite heterogeneous.

\section{Adjusted models}

Including significant variables from table 4 (ie, not sex or urban/rural habitation) a more complex model was fitted. Table 5 shows the results of fully-adjusted models using significant variables explored in table 4 . There has been minor attenuation in differences across area level SES. Similarly, association between age at diagnosis and rate of admission is also attenuated, and the difference across categories is more linear. The variability observed between county has moderately reduced and differences observed between large and small centres have reduced by $1.5 \%$. The largest attenuation is observed with respect to the effect of date of diagnosis, suggesting other factors explain the association between differential rates of admission and date of diagnosis observed in simple analyses.

\section{Sensitivity analyses}

Extensive sensitivity analyses were conducted including (1) a linear specification of area level SES in the model presented in table 5. The linear parameteristation resulted in an excess rate of admission of $16 \%$ per category increase comparing patients with T1D and populations controls (IRR $=1.163 ; 95 \%$ CI 1.108 to 1.222; $\mathrm{p} \leq 0.0001)$. However, this resulted in an increase in DIC of 30 points opposed to a fully categorical model, and was rejected as potentially misleading. (2) We also explored a categorical specification of the effect of age at diagnosis comparing cases to controls. Using a fully categorical parameterisation resulted in an approximately $15 \%\left[\log _{\mathrm{e}}(\mathrm{IRR})=-0.14\right]$ and $25 \% \quad\left[\log _{\mathrm{e}}(\mathrm{IRR})=\right.$ $-0.28]$ reduction in the rate of admissions comparing age at diagnosis between 5 and 10 year to under 5 years, and over 10 years with under 5 years, respectively. As the rate of reduction is linear on the $\log _{e}$ (IRR) scale, we opted for this simple specification. (3) We also refitted the model in table 5 without the county level variance, and effect sizes were very similar, yet the model DIC increased by eight points (results not shown). (4) To further investigate any migratory effects of individuals, we restricted follow-up time to when individuals were continuously resident in each county and to those who did not live in a county bordering England. Two hundred and thirty-seven individuals were removed from the analysis (234 who lived in border areas, and three who immediately departed from the area). Descriptive statistics of the remaining participants are described in table 1 .

The results for the sensitivity analyses are presented in online supplementary tables S2-S4. The differences observed in patterning of social class were largely attenuated, and only a small suggestion of an increase in admission rates in lower social classes. The differences in rate of admission by date of birth were also largely attenuated. However, the effect of reduction in admission rate in large centres, and increased age at diagnosis still persisted.

\section{DISCUSSION}

Meaning of the study's findings

This matched-cohort study demonstrates there is a $480 \%$ increase in the rate of all cause hospital admissions in children with T1D compared to those without. This increase represents a clear burden to families with diabetes and to the health system. Increased hospital admissions were associated with not being in the highest area level SES group, but also with being diagnosed in a small centre and at a younger age. This suggests that admission avoidance systems particularly targeted at the youngest age group and smaller centres might be most effective at reducing this burden.

\section{Strengths and weaknesses in relation to other studies}

An important strength of this study is the integration of the Brecon Group Register into the SAIL Databank, allowing all-cause admission rates in young people with diabetes to be examined through linkage to hospital admission records (PEDW) which ensures that all admissions will have been captured regardless of coding difficulties. The study is further strengthened by the large size and near-complete coverage $(97.6 \%)$ of those diagnosed with T1D in the Brecon Group Register, as shown by a previous independent capture-recapture exercise (see the Methods section). Furthermore, our ability to 
Table 4 Incidence rate ratio of hospital admissions between individuals with type I diabetes compared to normal population controls at different levels of exposures of interest

\begin{tabular}{|c|c|c|c|c|c|c|c|c|c|c|c|}
\hline \multirow{2}{*}{$\begin{array}{l}\text { Model } \\
\text { (DIC) }\end{array}$} & \multirow[b]{2}{*}{ Category } & \multicolumn{5}{|c|}{ Parameter estimates } & \multicolumn{5}{|c|}{ Variances } \\
\hline & & IRR & (SE) & $(95 \% \mathrm{Cl})$ & $p \leq$ & ESS & Level & Varian & e (SE) & $(95 \% \mathrm{Cl})$ & ESS \\
\hline \multirow{4}{*}{$1(22377)$} & Sex & & & & & & & & & & \\
\hline & Male (ref) & 5.619 & (1.100) & (5.039 to 6.258 ) & 0.001 & 3075 & 1 & - & - & - & - \\
\hline & Female (ref) & 1.058 & (1.005) & (0.905 to 1.238$)$ & 0.237 & 2953 & 2 & 1.260 & $(0.046)$ & (1.173 to 1.354$)$ & 6287 \\
\hline & & & & & & & 3 & 0.092 & $(0.023)$ & (0.048 to 0.138 ) & 1290 \\
\hline \multirow[t]{6}{*}{$2(22350)$} & SES & & & & & & & & & & \\
\hline & 1 (ref) & 4.794 & $(1.161)$ & (3.973 to 5.771 ) & 0.001 & 996 & 1 & - & - & - & - \\
\hline & 2 & 1.182 & (1.022) & (0.916 to 1.531$)$ & 0.100 & 1594 & 2 & 1.269 & $(0.046)$ & (1.181 to 1.363 ) & 5185 \\
\hline & 3 & 1.308 & (1.036) & (1.013 to 1.697 ) & 0.020 & 1516 & 3 & 0.077 & $(0.024)$ & (0.030 to 0.124$)$ & 814 \\
\hline & 4 & 1.139 & (1.017) & (0.886 to 1.465$)$ & 0.156 & 1416 & & & & & \\
\hline & 5 & 1.393 & (1.043) & (1.088 to 1.786$)$ & 0.004 & 1376 & & & & & \\
\hline \multirow[t]{4}{*}{3 (22370) } & Centre size & & & & & & & & & & \\
\hline & Small (ref) & 6.231 & (1.098) & (5.632 to 6.892$)$ & 0.001 & 3898 & 1 & - & - & - & - \\
\hline & Large & 0.821 & (0.984) & (0.700 to 0.965$)$ & 0.009 & 3979 & 2 & 1.264 & $(0.046)$ & (1.178 to 1.357 ) & 7327 \\
\hline & & & & & & & 3 & 0.109 & $(0.023)$ & (0.065 to 0.157 ) & 1501 \\
\hline \multirow[t]{4}{*}{$4(22354)$} & Age at diagnosi & s (years & & & & & & & & & \\
\hline & $<5$ (ref) & 7.843 & $(1.185)$ & (6.651 to 9.202 ) & 0.001 & 1336 & 1 & - & - & - & - \\
\hline & $5-10$ & 0.742 & (0.969) & (0.605 to 0.908$)$ & 0.002 & 1745 & 2 & 1.260 & $(0.046)$ & (1.174 to 1.353 ) & 7068 \\
\hline & $10+$ & 0.599 & $(0.948)$ & (0.490 to 0.737$)$ & 0.001 & 1629 & 3 & 0.104 & $(0.023)$ & (0.060 to 0.150$)$ & 1396 \\
\hline \multirow[t]{4}{*}{$5(22372)$} & Urban rural & & & & & & & & & & \\
\hline & Rural (ref) & 5.523 & (1.128) & (4.801 to 6.336 ) & 0.001 & 1766 & 1 & - & - & - & - \\
\hline & Urban & 1.073 & (1.006) & (0.907 to 1.277$)$ & 0.206 & 1760 & 2 & 1.267 & $(0.047)$ & (1.178 to 1.361$)$ & 6460 \\
\hline & & & & & & & 3 & 0.108 & $(0.024)$ & (0.062 to 0.157 ) & 1413 \\
\hline \multirow[t]{5}{*}{$6(22359)$} & Re county & & & & & & & & & & \\
\hline & Case & 5.785 & $(1.075)$ & (5.338 to 6.268 ) & 0.001 & 7049 & 1 & - & - & - & - \\
\hline & & & & & & & 2 & 1.269 & $(0.046)$ & (1.182 to 1.362$)$ & 6618 \\
\hline & & & & & & & 3 & 0.091 & $(0.023)$ & (0.047 to 0.139 ) & 1163 \\
\hline & & & & & & & 4 & 0.020 & $(0.011)$ & (0.007 to 0.050$)$ & 18169 \\
\hline \multirow[t]{6}{*}{7 (22335) } & Date of birth & & & & & & & & & & \\
\hline & $<90$ (ref) & 4.737 & (1.152) & (3.973 to 5.653 ) & 0.001 & 1033 & 1 & - & - & - & - \\
\hline & $90-94$ & 0.992 & (0.999) & (0.795 to 1.242 ) & 0.474 & 1395 & 2 & 1.265 & $(0.046)$ & (1.179 to 1.359 ) & 7334 \\
\hline & $95-99$ & 1.452 & (1.044) & (1.158 to 1.821$)$ & 0.001 & 1445 & 3 & 0.093 & (0.023) & (0.051 to 0.141$)$ & 1245 \\
\hline & 00-04 & 1.692 & (1.076) & (1.288 to 2.233 ) & 0.001 & 2000 & & & & & \\
\hline & $>05$ & 1.497 & (1.103) & (0.930 to 2.408$)$ & 0.049 & 6364 & & & & & \\
\hline \multicolumn{12}{|c|}{$\begin{array}{l}\text { All models use a multilevel Poisson model. Results are reported using the mean of the posterior distribution to indicate IRR, the SD of the } \\
\text { posterior chain is used to indicate the parameter SE, } 95 \% \text { posterior probability intervals }(95 \% \text { CI) represent the } 2.5 \text { th and } 97.5 \text { th centiles of } \\
\text { the posterior distribution, and directional posterior probabilities ( } p \leq \text { ). ESS indicates the effectiveness of MCMC chain mixing. Bayesian DIC is } \\
\text { used to indicate model fit. The reference category comparing the IRR between cases and controls is indicated, and the IRR of the exposure of } \\
\text { interest is represented by the interaction between the exposure of interest and case-control status. Level } 2 \text { variance indicates the } \\
\text { overdispersion parameter, level } 3 \text { variance indicates the matching criteria, and level } 4 \text { (model } 6 \text { ) variance indicates the county level variance. } \\
\text { DIC, Deviance Information Criterion; ESS, effective sample size; IRR, incidence rate ratio; SES, socioeconomic status. }\end{array}$} \\
\hline
\end{tabular}

match individuals from the Brecon cohort to healthy population controls has enabled us to adjust effectively for important confounding factors. Each young person with T1D was compared to five controls matched for location, week of birth and social class. The national approach and minimal cross-border flow avoids many biases and confounding factors that affect studies based on single clinics, or where patient flow between units may be high. Taking all these factors together, we believe that our design allows us to have a high degree of confidence that the excess of admissions seen is related in some way to diabetes and not to residual confounding.

Unlike many studies, we reported all-cause admission rates, not just metabolic consequences of poor diabetes self-care. We view this as a strength as it represents the total excess hospital-related healthcare costs for those with T1D and an overall measure of inconvenience for the patients and their families, although admittedly it provides less information on the reasons for the excess. Interventions aimed at improving outcomes for individuals with T1D and their families should consider all cause admissions as well as diabetes specific admissions.

A recent systematic review reported four studies of allcause admissions in children with T1D. ${ }^{22}$ Our findings are consistent with US studies ${ }^{23}{ }^{24}$ which report increased risks of hospitalisation with diabetes duration, younger age, underinsurance, lower socioeconomic class, presumed T1D phenotype, diagnosis at a community hospital versus tertiary care facility and an 


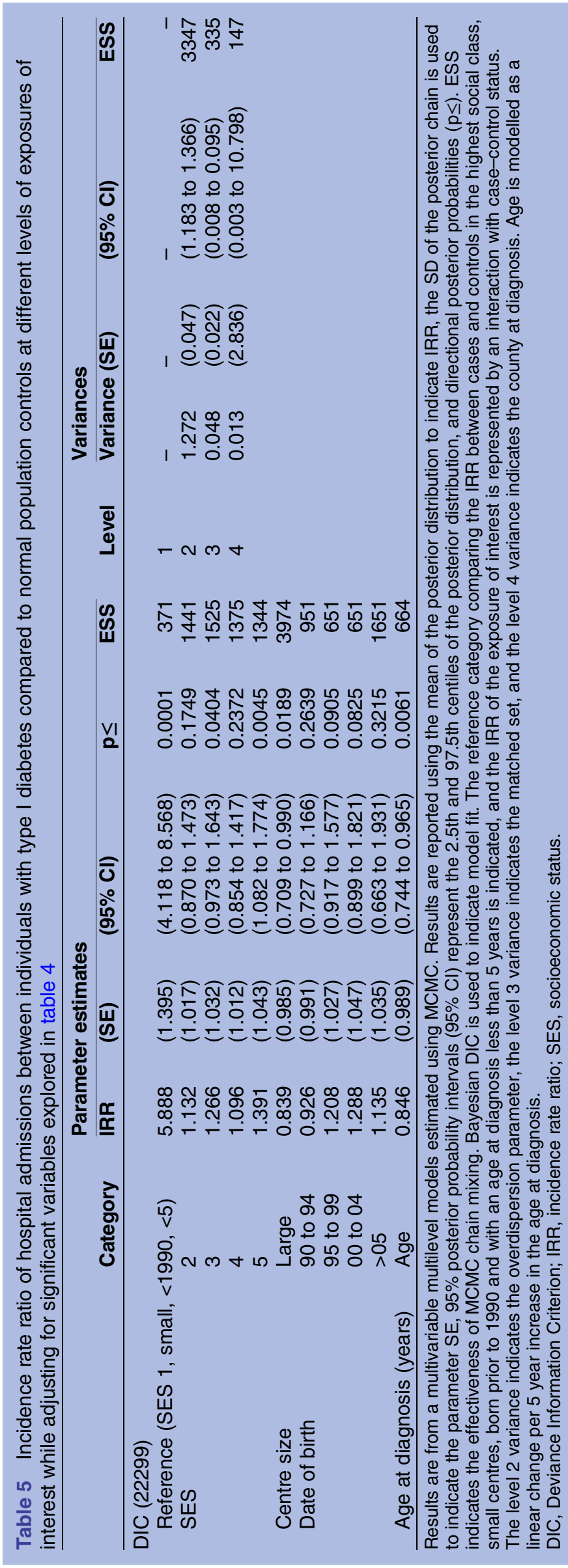

unemployed head of household. Importantly other studies have shown that the hospital admissions are associated with major complications in the longer term, ${ }^{25} 26$ and therefore understanding the mechanisms that underpin the observed increase are important.

An increased rate of admissions in those with T1D is unsurprising, and the increase in rate of admissions with a younger age at diagnosis has been previously reported. There are few studies reporting the magnitude of the effect on all-cause admission rates in a national cohort which account for major sources of confounding ${ }^{18}{ }^{19}$ but our findings are consistent with studies (albeit one not population-based $^{27}$ and the other a prospective population-based study confined to the first year after diagnosis ${ }^{28}$ ) from Germany which reported a similar increase in admission rates compared to the age-matched general population. Mechanisms responsible for this increase in rate may include greater anxieties of those parents, and healthcare professionals, caring for young children due to their ability to quickly metabolically decompensate. ${ }^{29}$ However, the implications of this finding suggest that targeted interventions, which may include additional support and education, for parents and healthcare workers, may help mitigate the increasing incidence of admissions in T1D preschool-aged children.

Understanding the differential rates of admission between large and small centres is clearly important to ensure outcomes for patients are optimised, as there may be significant risks associated with not admitting patients. Given the possible healthcare costs and implications for families, understanding the reason for higher admission rates in smaller units is clearly important. A limitation of this study is the definition of large and small treatment centre. Currently we use the centre of diagnosis as a proxy for centre of treatment. This is imperfect, because some participants move during the study, and a few may have been diagnosed at a location that is not their normal place of treatment. However, an analysis of outpatient records over time showed that in $88 \%$ of patient-years, participants were receiving some form of outpatient treatment in the same unit they were diagnosed.

The disproportionate effect of lower socioeconomic class on increased admission rates is unsurprising given the importance of education on diabetes outcomes and greater risks of comorbidity in disadvantaged families. ${ }^{30}$ This study provides mixed support for previous research in that there was no consistent trend of increasing risks with lower categories of area level SES comparing those with and without diabetes. The heterogeneity in results may be attributed to the crude assessment of area level SES, differential adherence to diabetes care, or current initiatives which attempt to reduce health inequalities.

Conversely this study did not show increased rates of hospital admission in women, which is in contrast to most other studies. ${ }^{422242531}$ The most recent National Paediatric Diabetes Audit in the UK shows that rates of hospital admission for diabetic ketoacidosis are generally higher in girls, including during puberty when maximal 
admission rates in childhood occur, and that these rates have increased over the past 5 years. ${ }^{32}$ Therefore, the absence of a difference in the IRR of admissions between the genders is difficult to explain at first glance. However, when comparing our results to studies which have performed similar analyses, it is interesting to note the similarities. ${ }^{28}$ For example, Icks $e t a l^{28}$ show no difference between the sexes when comparing the rate of admissions between patients with T1D and population matched controls (IRR 1.0; 95\% CI 0.76 to 1.31). However, when they compare the crude admission rates within patients with TID they observe that men have a lower rate of admissions compared to women (IRR 0.85; $95 \%$ CI 0.61 to 1.17 ). This pattern of results is nearly identical to our findings and suggests that the female-related hospital admissions in the general population are higher than men, and therefore a sex specific increase in rate of admission may not be isolated to patients with T1D.

\section{Unanswered questions and future research}

We have also shown that there is an increased rate of admission associated with diagnosis at small centres, which is consistent with other studies. ${ }^{24}$ However, understanding the reasons for this increased rate of admissions is more difficult, and a number of potential mechanisms may underpin this observation. For example, large tertiary centres may have more specialist medical or nursing staff available to resolve patient problems without need for admission, particularly through 'out of hours' support, or age-specific diabetes education packages. The increased distance between the patients' home and hospital in rural locations may reduce the threshold for admitting patients. However, as urban or rural classification was not associated with admission rates, it appears unlikely that distance from the treatment centre will be the primary mechanism which will explain the higher rates of admissions in smaller centres.

Differences in the management of T1D may also explain the heterogeneity in admission rates. However, the Brecon Group network ${ }^{8}$ of healthcare professionals are dispersed across all of Wales, and the sharing of protocols and expertise is widespread, which makes it unlikely that significant differences exist in philosophies (as opposed to resources) underpinning diabetes services across the country. Furthermore, in a study focusing on HbAlc, in Wales, it was shown there was no effect of centre size on glycaemic control. ${ }^{33}$

\section{CONCLUSIONS}

In conclusion, our population-based study provides robust evidence to date that young people with diabetes remain at substantial increased risk of all-cause hospitalisation. Further study is required to identify how clinical care should be targeted to improve outcomes and reduce healthcare-related costs, particularly in young patients, those from disadvantaged socioeconomic backgrounds and those being cared for in smaller centres. This is an area of great clinical importance, as patients admitted to hospital with diabetes aged under 30 years have a death rate nine times that of the general population. ${ }^{34}$

Author affiliations

${ }^{1}$ School of Clinical Sciences, University of Bristol, Southmead Hospital, Bristol, UK

${ }^{2}$ Centre for Health Information Research and Evaluation, College of Medicine, Swansea University, Swansea, UK

${ }^{3}$ Wrexham Academic Unit, Bangor University, Wrexham, Bangor, UK

${ }^{4}$ Diabetes Research Group, College of Medicine, Swansea University,

Swansea, UK

${ }^{5}$ Centre for Multi-level Modelling, University of Bristol, Bristol, UK

${ }^{6}$ Department of Child Health, University Hospital of Wales, Cardiff, UK

${ }^{7}$ Diabetes Research Group, Institute of Molecular \& Experimental Medicine,

School of Medicine, Cardiff University, Cardiff, UK

Acknowledgements The Brecon Group register was established through pump-priming financial support provided by NovoNordisk and subsequent funding from the Welsh Assembly Government. The register was initiated by Dr Michael Maguire and JWG who acknowledge the management of Aberdare Hospital. The authors are grateful for the loyal support of members of the Brecon Group in making annual data returns and for their contribution to interpretation of study findings, Ms Heather O'Connell and JNH for their support. The authors also acknowledge Professor Ronan Lyons and The Centre for Health Information Research and Evaluation, College of Medicine, Swansea University for their support and encouragement in analysing data from the SAIL Databank.

Contributors The analyses reported in this paper were initiated by JWG, SFW and CMD with the main statistical analyses being undertaken by AS and DT. JNH and JTW have been responsible for quality control of data collection in The Brecon Group Register and MDA and SL have facilitated analyses of the SAIL Databank. JWG, AS and DT drafted the manuscript and AS and JWG are joint guarantors of the content of the manuscript. All authors contributed to the interpretation of the final results and editing of the report for scientific content. All authors saw and approved the final version of the report.

Funding Brecon Group Register was supported initially by grants from NovoNordisk and subsequently the Welsh Assembly Government.

Competing interests JWG has received honoraria and expenses for contributions to advisory boards from Bayer and Lilly, speaker's fees from Pfizer and Merck Serono and support to attend scientific meetings from Ipsen. FSW has received honoraria and expenses for contributions to advisory board from Sanofi Aventis and speaker's fees from Lilly and Sanofi Aventis. CMD has been on advisory boards for GSK and Medtronic and given lectures supported by NovoNordisk, Sanofi-Aventis, Servier and Lilly. He has also been a consultant for Genzyme.

Provenance and peer review Not commissioned; externally peer reviewed.

Data sharing statement No additional data are available.

Open Access This is an Open Access article distributed in accordance with the Creative Commons Attribution Non Commercial (CC BY-NC 4.0) license, which permits others to distribute, remix, adapt, build upon this work noncommercially, and license their derivative works on different terms, provided the original work is properly cited and the use is non-commercial. See: http:// creativecommons.org/licenses/by-nc/4.0/

\section{REFERENCES}

1. Patterson CC, Dahlquist GG, Gyurus E, et al. Incidence trends for childhood type 1 diabetes in Europe during 1989-2003 and predicted new cases 2005-20: a multicentre prospective registration study. Lancet 2009;373:2027-33.

2. Edge JA, Swift PG, Anderson W, et al., Youth, Family Advisory Committee of Diabetes UK. Diabetes services in the UK: fourth national survey; are we meeting NSF standards and NICE guidelines? Arch Dis Child 2005;90:1005-9. 
3. Morgan CL, Peters JR, Dixon S, et al. Estimated costs of acute hospital care for people with diabetes in the United Kingdom: a routine record linkage study in a large region. Diabet Med 2010;27:1066-73.

4. Icks A, Holl RW, Giani G. Economics in pediatric type 1 diabetesresults from recently published studies. Exp Clin Endocrinol Diabetes 2007;115:448-54.

5. NHS Diabetes. Best Practice Tariff for Paediatric Diabetes (diabetes in children and young people aged 18 and under)-information for parents, children and young people. http://www.diabetes.nhs.uk/ networks/paediatric_network/best_practice_tariff_for_paediatric_ diabetes/\# (accessed 16 Jul 2013)

6. Gosden C, Edge JA, Holt RI, et al. The fifth UK paediatric diabetes services survey: meeting guidelines and recommendations? Arch Dis Child 2010;95:837-40.

7. Margeirsdottir HD, Larsen JR, Kummernes SJ, et al. The establishment of a new national network leads to quality improvement in childhood diabetes: implementation of the ISPAD Guidelines. Pediatr Diabetes 2010;11:88-95.

8. Lansdown AJ, Barton J, Warner J, et al. Prevalence of ketoacidosis at diagnosis of childhood onset type 1 diabetes in Wales from 1991 to 2009 and effect of a publicity campaign. Diabet Med 2012;29:1506-9.

9. Cartwright A, Wallymahmed M, Macfarlane IA, et al. The outcome of brittle type 1 diabetes-a 20 year study. QJM 2011;104:575-9.

10. Lyons RA, Jones $\mathrm{KH}$, John $\mathrm{G}$, et al. The SAIL databank: linking multiple health and social care datasets. BMC Med Inform Decis Mak 2009;9:3.

11. LaPorte RE, McCarty D, Bruno G, et al. Counting diabetes in the next millennium. Application of capture-recapture technology. Diabetes Care 1993;16:528-34.

12. Welsh Government (UK). Welsh Index of Multiple Deprivation 2008. http://wales.gov.uk/topics/statistics/theme/wimd/2008/; isessionid=0002A8CE866567F63DDEDF295C67D230?lang=en (accessed 10 Jul 2013).

13. John G. NHS Administrative Register. Cardiff: NHS Wales Informatics Service (UK). http://www.wales.nhs.uk/sitesplus/ documents/888/Gareth\%20John.pdf (accessed 10 Jul 2013).

14. Office of National Statistics (UK). Rural/Urban Definition (England and Wales). http://www.ons.gov.uk/ons/guide-method/geography/ products/area-classifications/rural-urban-definition-and-la/rural-urbandefinition--england-and-wales-/index.html (accessed $10 \mathrm{Jul}$ 2013).

15. Gelman A, Hill J. Data Analysis Using Regression and Multilevel/ Hierarchical Models. Cambridge: Cambridge University Press, 2009:335.

16. Browne WJ. MCMC Estimation in MLwiN v2.1. Centre for Multilevel Modelling, University of Bristol, 2009.

17. Rasbash J, Charlton C, Browne WJ, et al. MLwiN Version 2.1. Centre for Multilevel Modelling, University of Bristol, 2009.

18. Leckie G, Charlton C. Runmlwin: a Program to Run the MLwiN Multilevel Modeling Software from within Stata. J Stat Software 2013;52:1-40.
19. StataCorp. Stata Statistical Software: Release 12. College Station, TX: StataCorp LP, 2011.

20. Browne WJ, Draper D. A comparison of Bayesian and likelihood-based methods for fitting multilevel models. Bayesian Anal 2006;1:473-513.

21. Greenland S, Poole C. Living with $p$ values: resurrecting a Bayesian perspective on frequentist statistics. Epidemiology 2013;24:62-8

22. Angus VC, Waugh N. Hospital admission patterns subsequent to diagnosis of type 1 diabetes in children: a systematic review. BMC Health Serv Res 2007;7:199.

23. Charronprochownik D, Kovacs M, Obrosky DS, et al. Biomedical and psychosocial predictors of early rehospitalization among children with insulin-dependent diabetes-mellitus-a longitudinal-study. Diabet Med 1994;11:372-7.

24. Estrada CL, Danielson KK, Drum ML, et al. Hospitalization subsequent to diagnosis in young patients with diabetes in Chicago, Illinois. Pediatrics 2009;124:926-34.

25. Dahlquist G, Mollsten A, Kallen B, et al. Hospitalization for vascular complications in childhood onset type 1 diabetes-effects of gender and age at onset. Acta Paediatrica 2008;97:483-8.

26. Tomlin AM, Tilyard MW, Dovey SM, et al. Hospital admissions in diabetic and non-diabetic patients: a case-control study. Diabetes Res Clin Pract 2006;73:260-7.

27. Icks A, Rosenbauer J, Holl RW, et al. Hospitalization among diabetic children and adolescents and the general population in Germany. German Working Group for Pediatric Diabetology. Diabetes Care 2001;24:435-40.

28. Icks A, Rosenbauer J, Haastert B, et al. Hospitalization among diabetic children and adolescents and non-diabetic control subjects: a prospective population-based study. Diabetologia 2001;44(Suppl 3):B87-92.

29. Usher-Smith JA, Thompson MJ, Sharp SJ, et al. Factors associated with the presence of diabetic ketoacidosis at diagnosis of diabetes in children and young adults: a systematic review. BMJ 2011;343.

30. Zuijdwijk CS, Cuerden M, Mahmud FH. Social determinants of health on glycemic control in pediatric type 1 diabetes. $J$ Pediatr 2013;162:730-5.

31. Lipton RB, Zierold KM, Drum ML, et al. Re-hospitalization after diagnosis of diabetes varies by gender and socioeconomic status in urban African-American and Latino young people. Pediatr Diabetes 2002;3:16-22

32. National Paediatic Diabetes Audit Project Board. National Paediatic Diabetes Audit Report 2010-11. London: Royal College of Paediatrics and Child Health, 2012.

33. O'Hagan M, Harvey JN, Grp B. Glycemic control in children with type 1 diabetes in Wales influence of the pediatric diabetes specialist nurse. Diabetes Care 2010;33:1724-6.

34. Roberts SE, Goldacre MJ, Neil HA Mortality in young people admitted to hospital for diabetes: database study. BMJ 2004;328:741-2. 